\title{
PENGGUNAAN BUKU AJAR PENDIDIKAN JASMANI ADAPTIF PADA SEKOLAH LUAR BIASA KOTA BANJARMASIN
}

\author{
Muhammad Habibie ${ }^{1}$, Ari Trifitrianto ${ }^{2}$ \\ Universitas Islam Kalimantan Muhammad Arsyad Al Banjari Banjamasin ${ }^{1}$ \\ Universitas Islam Kalimantan Muhammad Arsyad Al Banjari Banjamasin ${ }^{2}$ \\ habibiem789@gmail.com
}

\begin{abstract}
ABSTRAK
Penelitian ini bertujuan untuk mengetahui penggunaan buku pedoman ajar dari guru Pendidikan jasmani di Sekolah Luar Biasa di Kota Banjarmasin. Metode yang digunakan dalam penelitian ini adalah survei dengan pendekatan kuantitatif deskriptif. Hasil penelitian menunjukan bahwa penggunaan buku pedoman atau buku ajar mata pelajaran pendidikan jasmani adaptif untuk anak berkebutuhan khusus adalah $0 \%$ atau belum ditemukan keberadaan buku pedoman tersebut dilapangan.
\end{abstract}

Kata Kunci: Buku Pedoman, Pendidikan Jasmani Adaptif, Anak Berkebutuhan Khusus

\section{ABSTRACT}

This study aims to determine the use of textbooks from physical education teachers in Special Schools in Banjarmasin. The method used in this research is a survey with a quantitative descriptive approach. The results showed that the use of manuals or textbooks for adaptive physical education subjects for children with special needs is $0 \%$ or the existence of these manuals has not been found in the field.

Keywords: Handbook, Adaptive Physical Education, Children with Special Needs

Dipublikasikan Oleh :

UPT Publikasi dan Pengelolaan Jurnal

Universitas Islam Kalimantan Muhammad Arsyad Al-Banjari Banjarmasin 


\section{PENDAHULUAN.}

Buku ajar adalah hasil buah pemikiran, pengalaman, serta analisis yang menjadi acuan dalam dunia Pendidikan. Seringkali buku ajar memiliki peran yang sangat penting sebagai sumber informasi, serangkaian kegiatan, dan bahan kajian. Buku ajar juga bermanfaat sebagai sumber rujukan literasi dalam penelitian.

Buku ajar merupakan segala bahan baik berupa informasi maupun alat, buku ajar tersusun secara sistematis yang ditampilkan secara utuh dari kompetensi yang akan dikuasai peserta didik dan digunakan dalam proses pembelajaran dengan tujuan perencanaan dan penelaahan implementasi pembelajaran (Prastowo, 2011). Buku ajar berisi tentang rangkaian pembelajaran yang tersusun sedemikian rupa merujuk pada kompetensi pencapaian sisawa demi tercapainya tujuan Pendidikan.

Buku ajar di sekolah maupun di perguraan tinggi disusun untuk membantu Guru, siswa, dan orang tua siswa dalam pembelajaran baik itu teori maupun praktek lapangan. Pada era Zaman ini, Guru dan siswa disarankan untuk memiliki dan membaca buku pedomana pembelajaran karena system informasi sangat mudah didapatkan. Oleh sebab itu ketersediaan buku ajar adalah komponen terpenting untuk kompetensi terhadap Pendidikan.

Pendidikan Jasmani potensinya lebih mendorong siswa dalam aktivitas Jasmani untuk meningkatkan kualitas gerak. Pendidikan jasmani berkontribusi untuk meningkatkan Kesehatan mental, membantu perkembangan sosial dan mental serta mendukung kinerja kognitif dan akedemik siswa (Hakim, 2017). Buku ajar Pendidikan jasmani di sekolah sering kita jumpai merujuk pada pengelompokkan kelas-kelas yang disusun oleh para ahli sedemikian khusus. Tapi peneliti tidak pernah melihat buku tentang Pendidikan jasmani yang sistematik untuk anak berkebutuhan khusus.

Anak Berkebutuhan Khusus atau yang juga dikenal lebih singkat dengan ABK merupakan individu unik terlahir dengan hambatan tertentu, baik berupa hambatan fisik, kognitif, sosial, emosi maupun Bahasa. Dulunya mereka lebih dikenal dengan istillah anak cacat, namun istillah ini sudah tidak boleh digunakan lagi sebab mendiskriminasi. ABK merupakan bagian dari generasi penerus bangsa yang sesuai dengan amanat konstitusi wajib mendapatkan layanan Pendidikan melalui Pendidikan khusus. Pendidikan yang mereka dapat diselenggarakan secara segregatif melalui sekolah luar biasa serta secara inklusif melalui sekolah umum (Sunardi dan Sunaryo, 2006).

Sama halnya dengan anak-anak lain, mata pelajaran yang ABK dapat di sekolah beragam mulai dari matematika, Bahasa Indonesia, Agama hingga Pendidikan Jasmani yang juga dikenal dengan olahraga. Pendidikan jasmani adalah salah satu disiplin ilmu penting di sekolah untuk anak berkebutuhan khusus (Sherrill 2004; Kiuppis 2016). Pendidikan jasmani untuk ABK yang lebih dikenal dengan istilah Pendidikan Jasmani Adaptif berperan dalam meningkatkan partisipasi ABK pada saat proses pembelajaran serta meningkatkan interaksi ABK dengan teman sebaya serta guru (Geidne dan Jerlinder: 2016). Disamping itu pendidikan jasmani adaptif berperan pula dalam meningkatkan kemampuan psikomotorik, afektif, dan kognitif ABK (Çelen, 2012; Koyuncuoğlu, 2015; Doydu, Çelen \& Çoknaz, 2013; Doydu \& Çoknaz, 2013; Doğu \& Altay, 2010). Perbedaan penting antara pendidikan jasmani untuk anak pada umumnya dengan untuk ABK terletak pada penyesuaian materi yakni sesuai hambatan belajar dan kebutuhan yang anak miliki. Bentuk penyesuaian materi ini salah satunya dapat dituangkan dalam buku pedoman guru dan siswa. Di lapangan buku pedoman yang dimaksud belum semuanya dapat ditemui, termasuk untuk pembelajaran Pendidikan jasmani.

\section{METODE}

Penelitian ini menggunakan pendekatan kuantitatif, dimana data dalam penelitian akan dijabarkan melalui angka-angka sebagai sumber data utama serta dilengkapi pula dengan penjabaran untuk mendeskripsikan makna dari data berupa angka-angka yang terkumpul. Metode yang digunakan untuk mengumpulkan data dalam penelitian ini adalah metode survey. Teknik pengumpulan data yang dipakai ialah wawancara, observasi serta dokumentasi. Narasumber dalam penelitian ini merupakan tenaga pengajar pendidikan jasmani di sekolah sekolah luar biasa (SLB) di Kota Banjarmasin. 


\section{HASIL}

Presentasi sekolah untuk anak berkebutuhan khusus yang menggunakan buku pedoman pembelajaran pendidikan jasmani adaptif di Kota Banjarmasin sangat rendah yakni 0\%. Dari tiga sekolah yang menjadi sumber data dalam penelitian ini didapat informasi bahwa tidak ada buku pedoman khusus yang digunakan dalam proses pelaksanaan pembelajaran pendidikan jasmani adaptif. Wawancara dengan salah satu pengajar pendidikan jasmani adaptif yang mengampu 7 kelas pada bulan Mei lalu memberikan gambaran faktual bahwa pembelajaran penjas dilakukan 100 menit dalam satu minggu, dalam satu semester melakukan 18-20 kali pembelajaran. Narasumber mengatakan bahwa tidak adanya buku ajar membuat proses pembelajaran menjadi tidak terarah. Proses pembelajaran yang dilakukan hanya berdasarkan pengelaman serta diskusi dengan wali kelas. Ketiadaan buku Pendidikan jasmani untuk anak berkebutuhan khusus membuat proses pembelajar terhambat. Hal ini menyebabkan kurangnya penguasaan terhadap materi pembelajaran Pendidikan jasmani untuk anak-anak berkebutuhan khusus di sekolah. Diperlukannya buku khusus untuk panduan proses pembelajar penjas agar tercapainya tujuan Pendidikan di sekolah tersebut.

\section{PEMBAHASAN}

Pengembangan bahan ajar penting dilakukan guru untuk meningkatkan kualitas dan efisiensi pembelajaran. Bahan ajar yang dikembangkan tersebut memiliki peran penting baik bagi guru maupun siswa (Sitepu, 2005). Pemilihan bahan ajar merupakan langkah awal seorang pendidik sebelum menggunakan bahan ajar tersebut dalam proses pembelajaran. Kesalahan dalam memilih bahan ajar akan mengakibatkan adanya tidak keseimbangan dalam proses pembelajaran. Hasilnya akan berakibat pada tidak tercapainya tujuan pembelajaran.

Sebagai salah satu bahan ajar cetak, buku ajar merupakan suatu paket belajar yang berkenaan dengan satu unit bahan pelajaran. Dengan buku ajar siswa dapat mencapai dan menyelesaikan bahan belajarnya dengan belajar secara individual (Sungkono, dkk, 2003). Peserta belajar tidak dapat melanjutkan ke suatu unit pelajaran berikutnya sebelum menyelesaikan secara tuntas materi belajarnya. Dengan buku ajar siswa dapat mengontrol kemampuan dan intensitas belajarnya. Buku ajar dapat dipelajari di mana saja. Lama penggunaan sebuah buku ajar tidak tertentu, meskipun di dalam buku ajar juga disebutkan waktu yang dibutuhkan untuk mempelajari materi tertentu (Tian Belawati, dkk. 2003).

Buku ajar yang dikenal juga dengan istillah buku pedoman pembelajaran merupakan bagian krusial dalam proses pelaksanaan pembelajaran termasuk pembelajaran pendidikan jasmani adaptif yang tujuannya adalah mengoptimalkan kebugaran anak-anak berkebutuhan khusus. Program pendidikan jasmani adaptif bagi anak berkebutuhan khusus yang memiliki keterbatasan kemampuan yang sangat bayak variasinya serta luas cakupannya, bahkan satu individu dengan individu lain tidak bisa disamakan program pembelajarannya (Hakim, 2017), menuntut pembatasan serta penyesuaian terhadap kebutuhan pembelajaran pendidikan jasmani adaptif sehingga memerlukan panduan khusus yang tersistematis berupa buku ajar.

Ketersediaan buku pedoman pembelajaran pendidikan jasmani adaptif harusnya mampu memfasilitasi kebutuhan belajar untuk optimalisasi kebugaran setiap anak berkebutuhan khusus yang berbeda-beda. Hal ini sesuai dengan amanah penggunaan kurikulum pada sistem layanan pendidikan untuk anak berkebutuhan khusus yaitu kurikulum yang fleksibel yang disesuaikan dengan kemampuan dan kebutuhan setiap siswa. Namun kenyataannya di lapangan buku pedoman pembelajaran pendidikan jasmani adaptif masih belum tersedia, yang ditemukan hanya berupa materi terintegrasi dalam bagian kecil dari buku-buku tematik belajar siswa. Hal ini dirasa tidak mencukupi kebutuhan panduan untuk pembelajaran jasmani adaptif yang optimal.

Pada hakikatnya seorang pendidik termasuk yang mengajarkan pendidikan jasmani adaptif harus merencanakan tujuan pembelajaran yang akan diajarkan, kontent materi yang relevan hingga bagaimana cara mengimplementasikan proses pembelajaran agar mampu memfasilitasi beragamnya kebutuhan belajar anak berkebutuhan khusus. Kembali hal yang sampai saat ini harus dimaklumi adalah belum tersedianya buku panduan atau pedoman pembelajaran jasmani adaptif yang aplikatif di lapangan. Kondisi demikian sedikit banyaknya membuat pendidik kesulitan untuk melakukan proses pembelajaran, terkadang mereka hanya terkesan menerka-nerka alur proses belajar yang diimplementasikan. Ketidaksesuaian pemberian materi ajar dengan kebutuhan peserta didik juga riskan terjadi.

Sumber data dilapangan yang menunjukkan ketiadaan penggunaan buku pedoman pembelajaran pendidikan jasmani adaptif turut merefleksikan ketidakseragaman proses pembelajaran yang dilakukan. Jika 
terus dibiarkan terjadi dampak dari temuan ini akan semakin meluas padahal optimalisasi proses pembelajaran adalah suatu keharusan.

\section{KESIMPULAN}

Berdasarkan hasil penelitian yang dilakukan di Sekolah Luar Biasa Kota Banjarmasin maka presentasi keberadaan buku pedoman khusus pembelajaran pendidikan jasmani adaptif untuk anak berkebutuhan khusus adalah $0 \%$ atau dengan kata lain di lapangan masih belum tersedia buku panduan yang berfungsi sebagai acuan dalam proses pembelajaran pendidikan jasmani adaptif.

\section{DAFTAR PUSTAKA}

Arif Rohman Hakim. (2017). Memuliakan Anak Berkebutuhan Khusus Melalui Pendidikan Jasmani Adaptif. Jurnal Ilmiah PENJAS, 3, 2442-3874.

Çelen, A. (2012). The effects of volleyball classes taught through sports education model on cognitive, affective and psychomotor achievement skills of students. Abant Izzet Baysal University. Unpublished doctoral dissertation. Retrieved from YÖK Tez Merkezi.

Doğu, S., \& Altay, F. (2010). The effect of sport education model on development of rhythm skills in dance education. Book of Abstracts of 11. International Sports Sciences Congress 192-193, Antalya, Turkey.

Doydu, İ., Çelen, A., \& Çoknaz, H. (2013). The effect of the sports education model on the attitudes of students towards physical education and sports. E-International Journal of Educational Research, 4(2), 99-110

Geidne, S., \& Jerlinder, K. (2016). How sports clubs include children and adolescents with disabilities in their activities. A systematic search of peer-reviewed articles. Sport Science Review, 25(1-2), 2952. doi:10.1515/ssr-2016-0002

Kiuppis, F. (2016). Inclusion in sport: disability and participation. Sport in Society, 21(1), 421. doi:10.1080/17430437.2016.1225882

Koyuncuoğlu, K. (2015). The effects of gymnastics course taught through sports education model on students ${ }^{\text {ee }}$ cognitive, affective, and psychomotor attainment levels. Doctoral dissertation. Retrieved from YÖK Tez Merkezi.

Sherrill, C. (2004). Adapted physical activity, recreation and sport: Crossdisciplinary and lifespan. (6th ed.). Boston, MA: WCB/McGraw-Hill. Special Educational Needs in Europe. Teaching Language to Learners with Special Needs. European Commission, DG EAC 2303 LOT 32005.

Sitepu. (2005). Memilih Buku Pelajaran. Jurnal Pendidikan Penabur, (online), vol 4, (http://www.bpkpenabur.or.id/files/Hal.113126\%20 Memilih\%20Buku\%20Pelajaran. pdf)

Sunardi dan Sunaryo. (2006). Intervensi Dini Anak Berkebutuhan Khusus. Jakarta: Dirjen Dikti.

Sungkono, dkk. (2003). Pengembangan Bahan Ajar. Yogyakarta: FIP UNY.

Tian Belawati, dkk. (2003). Pengembangan Bahan Ajar . Jakarta: Pusat Penerbitan UT.

Dipublikasikan Oleh : 
Dipublikasikan Oleh :

UPT Publikasi dan Pengelolaan Jurnal

Universitas Islam Kalimantan Muhammad Arsyad Al-Banjari Banjarmasin 